\title{
Abordagem gestáltica: um resgate da dimensão sensível do Humano
}

\section{Eleonôra Torres Prestrelo}

Professora Assistente do Instituto de Psicologia da Universidade Estadual do Rio de Janeiro/UERJ - Rio de Janeiro, RJ, Brasil

Editora do Dossiê Abordagem Gestáltica

\section{Laura Cristina de Toledo Quadros}

Professora Assistente da Graduação em Psicologia do Centro Universitário Celso Lisboa/CUCL - Rio de Janeiro, RJ, Brasil

Editora Associada do Dossiê Abordagem Gestáltica

“Nenhuma época acumulou sobre o homem tão numerosos e diversos conhecimentos como a nossa [...] Nenhuma época conseguiu tornar esse saber tão pronta e facilmente acessível. Mas nenhuma época tampouco soube menos o que é

A Psicologia desenvolveu-se historicamente num cenário de expansão científica marcada pela ênfase na comprovação dos fatos e pela linguagem matemática. No campo das chamadas "Ciências Naturais", onde a objetividade positivista e as explicações referendadas no paradigma mecanicista-cartesiano geravam buscas pelo domínio e a crença numa suposta "verdade absoluta".

A Revolução Industrial, as descobertas da Medicina, a evolução da Física, cada vez mais apontavam para a possibilidade do Homem dominar os mistérios do Universo, antes vinculados apenas aos dogmas religiosos.

Assim, a construção da Psicologia em busca do status de Ciência também se apressava em respaldar-se numa objetividade, tentando achar respostas plausíveis para questões voltadas à cognição, voltando-se para desvendar como o Homem apreende e organiza o conhecimento. Definir as Leis de conexões que constituem a mente humana, responsáveis pela "função superior", ou seja, a racionalidade que definiria o humano, diferenciando-o dos outros animais.

Neste contexto, a Psicologia busca respostas para que a Ciência também inclua o Homem como objeto passível de controle, compreendendo o mundo como uma grande máquina incessante e o ser humano como uma das engrenagens que mantém esta estrutura mecânica funcionando. 
Se uma resposta absoluta fosse, de fato, possível e suficiente, talvez a Psicologia não ultrapassasse as afirmações deterministas ou ainda estaria restrita ao estudo do comportamento observável.

$\mathrm{Na}$ passagem do século $\mathrm{XIX}$ para o século $\mathrm{XX}$, outras áreas de conhecimento, em especial no contexto social, rebelaram-se contra esse "engessamento", não mais religioso, mas ditado pelo poder incontestável de um modelo científico factual e elitista, que desconsiderava aspectos culturais, históricos e subjetivos.

A Psicologia deparava-se com situações que não cabiam nas explicações comportamentalistas e o compromisso com o sofrimento humano não objetivável moveram estudiosos a buscar novas respostas, encontrando também novas perguntas. A Psicanálise é um dos destaques deste momento histórico, fundando uma possibilidade de intervenção fundamentada na escuta e na palavra. (FREUD, 1977) O jovem Frederick Perls, judeu alemão, médico neurologista, já trazia a irreverência e a ousadia em sua trajetória pessoal e, com sua inquietude e visão crítica da realidade, desde cedo aproximou-se de idéias inovadoras, sendo influenciado pela arte, a contracultura e o pensamento não linear que transcendesse as explicações causais, podendo acolher perguntas sem respostas, ou melhor, perguntas que abrangessem tantas respostas que levavam à possibilidade de reconhecermos a indeterminação e a dinâmica da dimensão humana, que não cabiam em categorizações e rótulos definitivos ou definidores.

Perls fez parte da segunda geração de psicanalistas que já começava a repensar certas "verdades" Freudianas. Porém, devido à pouca possibilidade de interlocução ou mesmo interferências no que já estava estabelecido, suas idéias foram pouco escutadas e consideradas entre os colegas e o próprio Freud, que contestou a descaracterização de alguns de seus construtos. (PERLS, 1981)

Rompendo, então, com a prática psicanalítica, Perls repensa seu modo de atuação, sofrendo diversas transversalidades representadas por seu encontro com Kurt Goldstein, criador da teoria organísmica, seu percurso como ator amador na juventude, seu encontro sentimental e intelectual com Laura Lorne, doutora em Psicologia vinculada aos gestaltistas Kofka, Kohler e Wertheimer, além de ter passado pela análise com W. Reich e supervisão com Karen Horney. (TELLEGEN, 1984)

Porém, a ascensão nazista na Alemanha dos anos 30 dispersou um núcleo de intelectuais que entraram em rota de fuga ou por sua origem judaica ou por seus ideais antifascistas. Este fato, que marca a história da humanidade, constituiu-se numa pulverização de idéias que passaram a ser geradas de forma mais solitária, sofrendo interferências políticas, afetivas e morais, causando um grande impacto na força intelectual, principalmente da Europa. 
Os EUA despontavam como a terra das grandes oportunidades e abrigaram muitos desses "fugitivos" que, distante de sua cultura, língua nativa e marcados pela interrupção prematura das discussões acerca de novas propostas para a intervenção clínica, buscaram interagir com o "Novo Mundo", que se caracterizava pelo pragmatismo das soluções mais diretas e efetivas e pelo otimismo de um país que não conheceu a destruição e a privação das nações diretamente atingidas pelos horrores da II Guerra.

Perls refugiou-se inicialmente na África do Sul e, posteriormente, também emigrou para os EUA. Podemos dizer que, neste país, ele não abandonou suas raízes européias, mas seu pensamento de vanguarda encontrou um eco fundamental na explosão dos anos 60, que transpiravam a necessidade de ressaltar a autenticidade, a transparência, a espontaneidade.

O chamado "mundo civilizado" demonstrava, após sucessivas guerras, necessidade de expressar a liberdade e questionar as decisões políticas articuladas pelo poder econômico e pela doutrina maniqueísta centralizada na luta do "bem" contra o "mal", sem espaço para debates e questionamentos.

A juventude não estava mais disposta a se submeter simplesmente, sem reivindicar seu direito à própria expressão e intervenção, pois eles precisavam usufruir o presente e acreditar num futuro.

Perls, já na última década de sua rica trajetória pessoal e profissional, foi responsável por transmitir e difundir uma abordagem de atuação, que não era meramente expressiva e teatral como alguns erroneamente imaginavam. Tão pouco era uma abordagem inconsistente ou carente de conceituação teórica. Era, de fato, uma abordagem constituída na ação, mas fundamentada na articulação existencial-fenomenológica, que compreende o Homem como um processo passível de transformação constante e, portanto, integrado à idéia de uma existência indefinida, indeterminada e constituída pelas potencialidades do "vir a ser".

Uma das características fundamentais da abordagem gestáltica é enfatizar o processo de awareness (dar-se-conta, conscientizar-se), compreendendo que o Homem deve estar atento a si próprio, mantendo a presentificação da experiência e sua integração à ordem do vivido, através do fluxo de consciência.

Este continuum de awareness ressaltado por Perls (1981) revela a importância de estar atento às formas de expressão, mobilização e ação, para o reconhecimento das fronteiras de contato e, conseqüentemente, ampliando a responsabilidade sobre as formas de estabelecer relações e de estar no mundo.

A Gestalt-terapia transpôs a filosofia existencialista para a prática clínica, principalmente através do experimento. Cabe aqui esclarecer que o experimento não é uma técnica que pode ser recortada de um sistema epistemológico. Este é um erro que foi reproduzido durante 
anos, gerando uma série de equívocos em relação à Abordagem Gestáltica.

O experimento não é uma superprodução ou um mero recurso de expressão catártica. Na verdade, ele precisa ser manejado de forma sutil, pois seu diferencial consiste em permitir que o cliente experiencie a si mesmo através do que expõe, integrando sua fala à percepção de seu sentimento, sua postura corporal e suas potencialidades e limitações no contexto de sua experiência viva. Assim, ele reconfigura sua perspectiva, ampliando seu fluxo de consciência na ação em que vive.

Perls desenvolve uma metodologia de vanguarda que preconiza uma visão holística de Homem, integrando corpo, mente e contexto social. Portanto, apesar, de sua irreverência, legitimou a sensibilidade e a intuição como modos de intervenção em psicoterapia.

Desconstrói-se a pretensão de uma verdade para acolhermos as incertezas que permeiam a existência humana, revelando a atualidade de uma abordagem que atua na relação, baseada no princípio da dialogicidade (BUBER, 1977) e o reconhecimento das fronteiras de contato. Assim, afastando-se da idéia de um indivíduo isolado, ela possibilita o espaço relacional onde o "eu" e o "outro" constitui uma realidade integrada, interdependente, porém singularizada no reconhecimento dos limites de cada um no seu contexto de vida. O espaço terapêutico torna-se, antes de tudo, o espaço do vivido:

A relação entre figura e fundo na saúde é um processo de emergência e recuo permanentes, mas significativos. Assim, a interação entre figura e fundo torna-se o centro da teoria [...] atenção, concentração, interesse, preocupação, excitamento e graça são característicos da formação saudável de figura/fundo; enquanto confusão, tédio, compulsões, fixações, ansiedade, amnésias, estagnação e acabamento são indicadores de uma formação figura/fundo perturbada. (PERLS; HEFFERLINE; GOODMAN, 1997, p.34)

O caráter vivencial introduzido pela Gestalt Terapia permitiu o surgimento de uma prática fundamentada não apenas no Diálogo, em seu sentido Buberiano (op. cit), mas também uma intervenção que, para além das palavras, mobiliza os sentimentos resgatando o sofrimento humano em sua dimensão mais sensível.

Assim, ela constituiu-se numa forma de trabalho que, ao mesmo tempo instigante, exige densidade e compreensão de suas raízes filosóficas, para que não se reduza a um mero tecnicismo.

Hoje, acreditamos que transcendemos a necessidade de defender a Abordagem Gestáltica de críticas superficiais, visto que ela já ocupa um espaço importante dentre as práticas psicoterápicas e no universo acadêmico, tanto no Brasil como em outros países como França, Estados Unidos, I tália e toda a América Latina. 
No Brasil, seu crescimento deve-se, sobretudo, ao esforço de muitos pioneiros e figuras emblemáticas que "ousaram" introduzir uma nova interlocução, no âmbito acadêmico, propiciando a ação do conhecimento a outras linguagens e práticas.

No mundo contemporâneo, onde as certezas e a razão não são as únicas fontes de sustentação, vale ressaltar que Perls já compreendia a importância do reconhecimento das diferenças e a simultânea integração do Homem ao seu contexto, sem idealizações e sem as normatizações que diluem a singularidade. Essa perspectiva coadunase com o pensamento de Morin (2002, p. 65), quando este nos aponta:

Em todas as coisas humanas a extrema diversidade não deve mascarar a unidade, nem a unidade básica mascarar a diversidade: a diferença oculta a unidade, mas a unidade oculta as diferenças. Deve-se evitar que a unidade desapareça quando surge a diversidade e vice-versa.

Perls foi, sem dúvida, um visionário e, abriu-se para compreender o Homem dentro de uma perspectiva integrada e contextualizada, afastando-se dos determinismos. Assim, ele já preconizava a possibilidade da integração, resguardando-se às diferenças e o espaço do possível.

O homem que pode viver um contato íntimo com sua sociedade sem ser tragado por ela nem dela completamente afastado é um homem bem integrado [...]. O objetivo da Psicoterapia é justamente criar tal homem (PERLS, 1981, p.40)

\section{Referências Bibliográficas}

BUBBER, M. Eu - tu. São Paulo: Cortez e Moraes, 1977.

FREUD, S. Obras completas. Rio de Janeiro: I mago, 1977.

HEIDEGGER, M. Ser y Tiempo. Tradução de Jorge Eduardo Rivera. Santiago do Chile: Editorial Universitária, 1997.

MORIN, E. O método 5, A humanidade da humanidade. Porto Alegre: Ed. Sulina, 2002.

PERLS, F. A Abordagem Gestáltica e Testemunha Ocular da Terapia. Rio de Janeiro; Zahar, 1981.

PERLS, F; HEFFERLINE, R; GOODMAN, P. Gestalt-Terapia.São Paulo: Summus, 1997.

TELLEGEN, T. Gestalt e grupos. São Paulo: Summus, 1984.

\section{Endereço para correspondência}

Eleonôra Torres Prestrelo

Universidade do Estado do Rio de Janeiro - UERJ, Rua São Francisco Xavier, 524, bloco B, sala 10.019, 10 ${ }^{\circ}$ andar, CEP 20550-013, Rio de Janeiro-RJ, Brasil Endereço eletrônico: eprestrelo@gmail.com 
Laura Cristina de Toledo Quadros

Centro Universitário Celso Lisboa - CEUCEL, Rua 24 de Maio, 797, Sampaio, CEP 20950-091, Rio de Janeiro-RJ, Brasil

Endereço eletrônico: laura@softconsultoria.com.br 